\title{
Creating a Successful Teacher's Profile as Perceived by Students
}

\author{
P. SRINIVASAN ${ }^{1, *}$, M. KAVIPRIYA ${ }^{2}$ \\ ${ }^{1}$ Assistant Professor Department of Education Tamil University Thanjavur \\ ${ }^{2}$ MPhil Scholar Department of Education Tamil University Thanjavur \\ *Corresponding author: seenuthilaka@yahoo.com
}

Received December 02, 2014; Revised December 15, 2014; Accepted December 22, 2014

\begin{abstract}
The present investigation is an attempt to create a successful teacher's profile as perceived by school students. The successful teachers were identified informally by enquiring the students. Then students of successful teachers are taken as samples. Data was collected by face-to-face interview with every sample. Every student's response was recorded. The sample's responses were in a statement. These statements refer a particular character of a teacher. Therefore the investigators have given a particular term for such statements. The terms are treated with percentage analysis. A database of successful teacher's profile is created in conclusion, which contains 31 characters of a teacher.
\end{abstract}

Keywords: teacher profile, successful teacher, students perception

Cite This Article: P. SRINIVASAN, and M. KAVIPRIYA, "Creating a Successful Teacher's Profile as Perceived by Students.” American Journal of Educational Research, vol. 2, no. 12 (2014): 1237-1243. doi: 10.12691/education-2-12-17.

\section{Introduction}

Education in its general sense is a form of learning in which knowledge, skills and habits of a group of people are transferred from one generation to the next generation through teaching and training. Education generally takes place under the guidance of others, but may also be autodidacts. The education is the fourth necessity for man after food, clothing and shelter, in today's competitive world. Education is indeed a powerful tool to combat the cut-throat competition that humanity faces in life [1].

The main aim of education is to provide integrated development for the individual person. Acquiring the capacities of understanding, appreciation and expression through word and action are the fundamental aims of education. Aims of education should make children selfconfident and self-dependent, and to make them physically and mentally strong.

A school is an institution designed for the teaching of students under the direction of teachers. Schools are one of the first places where children's behavior and future professional success is shaped. A teacher is a person who provides education for students [2]. Teachers are carriers of positive behavior towards students [3]. The school without a teacher is just like a body without the soul. In short, education is an essential concomitant of all human societies [1].

Students' achievement directly involves teachers' quality and competence. The great teachers work tirelessly to create a challenging, nurturing environment for students. A successful teacher's have a special quality of teaching strategy, classroom environment and psychological basis.
Who is the successful teacher from the students' point of view? The answer to this question is important for every person who opts for the teaching profession. This answer motivates a student teacher / teacher to become a successful teacher. Hence, in this study, an attempt is made to create a successful teacher's profile as perceived by students.

\section{Background}

Teacher's quality influences students' outcome. Linda Darling-Hammond [4] has found out students' characteristics such as poverty, non-English language status, and minority status negatively correlate with student outcomes. Teacher quality characteristics such as certification status and degree in the field to be taught are very significant and positively correlated with student outcome.

Successful teachers are role model of their students. Mittendorff [5] has indicated that teachers struggle with the transition towards becoming a career guide for students, and aspects influencing the transition into this new role need to be considered.

Teacher's professional ethics do not depend with their experience. Canrinus [6] has concluded that profiles differed significantly regarding the indicators of teachers' professional identity. Teachers belonging to the profiles did not significantly differ in their amount of experience.

Schools environment highly impact the teacher's working condition. Tanaka \& Chisato [7] have examined the complex environment in which teachers work and the important role of the authorities in influencing their working conditions. 
Rand Education [8] also identified that, teachers matter more to student achievement than any other aspect of schooling. Non-school factors do influence students' achievement, but they are largely outside a school's control. Effective teachers are best identified by their performance, not by their experience or background. Effective teachers lead to stay effective even when they change schools.

Douglas R. Eikermann [9] gives sixteen traits of excellent teachers such as knowledge of the subject matter, patience, intellectual curiosity, confidence, compassion, achievement, planning, awareness, mentorship, maturity, community involvement, organization, vision, context, mission and enthusiasm.

\section{Objectives of the Study}

The objectives of the study are

- To find the successful teachers

- To find out the successful teacher's students

- To interview the students

- To create a profile of successful teacher as perceived by students.

\section{Operational Definition of Key Terms}

Following are the operational definitions of key terms.

\subsection{Profile}

Drawing an outline of one's characteristics is called profile.

\subsection{Successful Teacher}

A teacher who has a personal human relationship with every student and who genuinely cares about each student for their success.

\section{Population of the Study}

The population of the present study is the students of successful teachers who are studying in higher secondary schools in Thanjavur and Pudukkottai districts of Tamilnadu, India.

\section{Sample of the Study}

The sample consists of 60 school students of successful teachers. A Purposive sampling technique is used for this study. The distribution of sample is given in Table 1 .

Table 1. Distribution of Sample

\begin{tabular}{|c|c|c|c|c|}
\hline \multirow{2}{*}{ S. No. } & \multirow{2}{*}{ Name of the School } & \multirow{2}{*}{$\begin{array}{l}\text { No. of Successful } \\
\text { Teachers }\end{array}$} & \multicolumn{2}{|c|}{ No. of the students } \\
\hline & & & No. & Code No. \\
\hline 1 & Boys Govt. Higher Sec. School, Vallam. & 1 & 5 & 1A,1B,1C,1D,1E \\
\hline 2 & Girl’s Government Higher Secondary School, Vallam. & 2 & $16(8+8)$ & $\begin{array}{c}2 \mathrm{~A}, 2 \mathrm{~B}, 2 \mathrm{C}, 2 \mathrm{D}, 2 \mathrm{E}, \\
2 \mathrm{~F}, 2 \mathrm{G}, 2 \mathrm{H}, 2 \mathrm{I}, 2 \mathrm{~J}, \\
2 \mathrm{~K}, 2 \mathrm{~L}, 2 \mathrm{M}, 2 \mathrm{~N}, 2 \mathrm{O}, 2 \mathrm{P}\end{array}$ \\
\hline 3 & Kalaimagal Matric Higher Secondary School, Vallam. & 2 & $10(5+5)$ & $\begin{array}{l}\text { 3A,3B,3C,3D,3E } \\
\text { 3F,3G,3H,3I,3J }\end{array}$ \\
\hline 4 & Government Higher Secondary School, Sengipatti. & 1 & 5 & $4 \mathrm{~A}, 4 \mathrm{~B}, 4 \mathrm{C}, 4 \mathrm{D}, 4 \mathrm{E}$ \\
\hline 5 & $\begin{array}{l}\text { KarpagaVinayaga Matric Higher Secondary School, Sivapuram, } \\
\text { Pudukottai. }\end{array}$ & 1 & 8 & $\begin{array}{l}\text { 5A,5B,5C,5D,5F, } \\
\text { 5G,5H,5I }\end{array}$ \\
\hline 6 & Fr.Antony Matric Higher Secondary School, Vallam. & 1 & 7 & $\begin{array}{l}\text { 6A,6B,6C,6D,6E, } \\
\text { 6F,6G }\end{array}$ \\
\hline 7 & Kamala Subramaniyam Matric Higher Secondary School, Thanjavur. & 1 & 4 & 7A,7B,7C,7D \\
\hline 8 & Sacred Heart Girl's Higher Secondary School, Thanjavur. & 1 & 5 & 8A,8B,8C,8D,8E \\
\hline & Total & 10 & 60 & \\
\hline
\end{tabular}

The samples are being coded. Code numbers in Table 1 represent the sample; each sample was given a code number instead of using their names, for instance, $1 \mathrm{~A}$ can be segregated into numeral 1 and alphabet A. Numeral 1 refers to the serial number of the school and alphabet $A$ refers to the individual sample. The same way $1 \mathrm{~B}$ can be segregated into numeral 1 and alphabet B. Numeral 1 refers to the serial number of the school and alphabet $\mathrm{B}$ refers to the individual sample and so on.

\section{Methodology}

Both qualitative and quantitative methods were used; therefore the methodology adopted in this study is mixed method. In qualitative approach, content analysis and interview were used. In quantitative approach, percentage analysis was used.

\section{Tool for the Study}

Interview questionnaire is used as a tool for this study. Unstructured interview questions are used to collect data.

\section{Data Analysis}

The sample selection was based on the successful teacher. The successful teachers were selected informally by enquiring the students. Then samples were selected from the students of successful teachers. Every student's response was noted and then their responses are analyzed.

The responses of the sample were in the form of statements. These statements refer a particular character of successful teachers. Therefore the investigators have coined a particular term which suits for such statements. 
Finally, the terms are treated for percentage analysis. Following Figure 1 shows the percentage of terms in descending order.

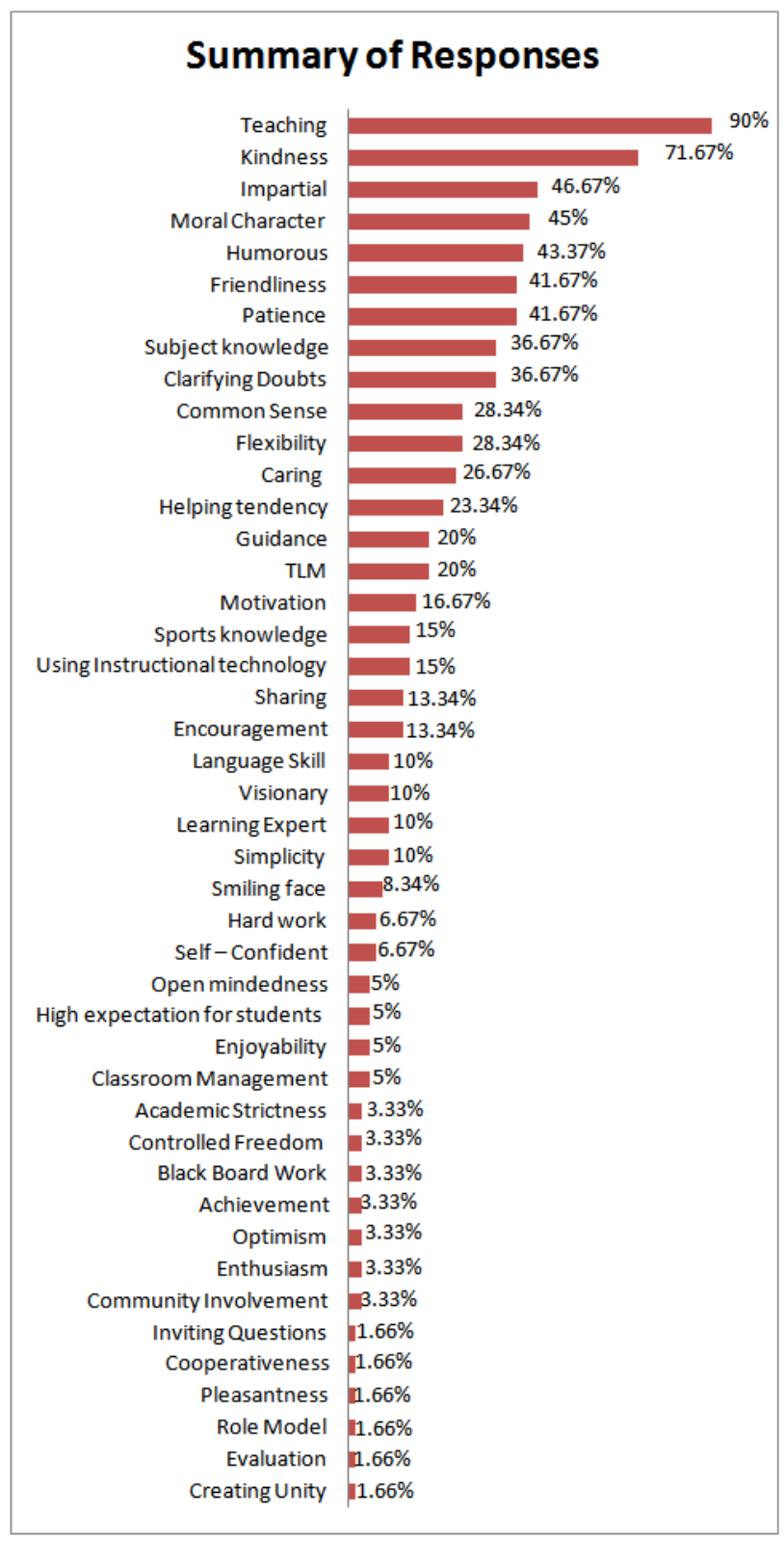

Figure 1. SUMMARY OF RESPONSES

\section{Successful Teacher's Profile}

Figure 1 shows summary of sample's responses. Samples explained about different characters of their teachers. Summary of responses has 44 characters of a successful teacher. The investigators have filtered the successful teacher's characters from the Figure 1. The character which has tallied 5\% and above is selected for the successful teacher's profile and the character which has below $5 \%$ is omitted. One or two samples accounted for less than $5 \%$ of the total sample. Hence those responses are omitted. After percentage analysis, following profile is created for successful teachers as perceived by students. The successful teacher's profile now has 31 characters for teachers. Successful teacher's profile as perceived by students is given in the following Figure 2.

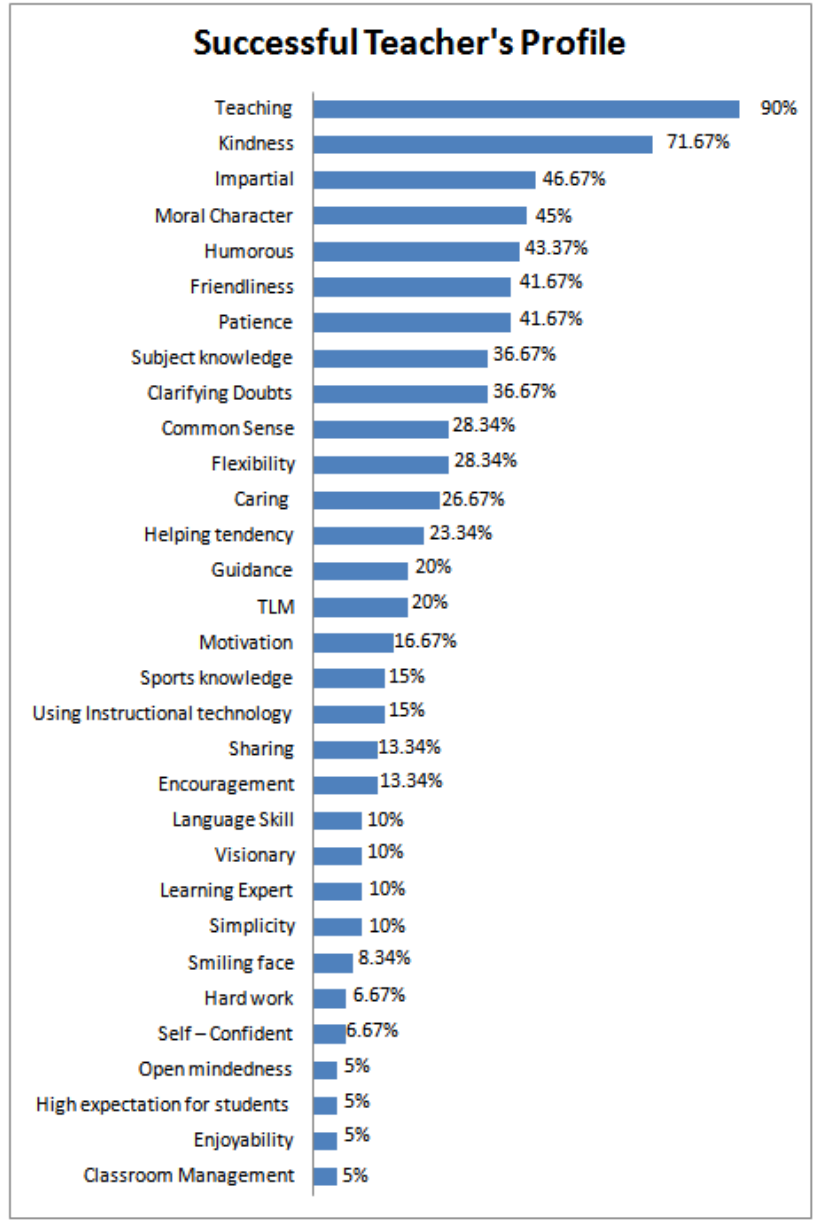

Figure 2. SUCCESSFUL TEACHER'S PROFILE

\section{Discussion}

Discussion of each and every character of the successful teacher's profile is as follows.

\section{Teaching}

Teaching is an act of instructing.

The samples in this study, told different aspects of their teacher's teaching. However, most of the samples, 54 out of 60 , indicated this character. For example, samples (1A, 2A, 2C, 2E, 2G, 2N, 3A, 4B, 4D, 6A, 6E, 6F, 7A, 7B, 7D and $8 \mathrm{E}$ ) said that,

"My teachers' teaching is well"

Samples (1C, 3H and 7C) stated that,

"My teachers teaching is unique one"

Samples (4C, 4E, 5A, 5D, 5G, 8A and 8D) stated that,

"My teachers teaching is easily understandable and motivating”

Similar responses like the above were coined under the word "Teaching” by investigators.

\section{Kindness}

Kindness means the quality of being warmhearted, considerate, humane and a pleasant disposition.

As shown in table-2, 43 out 60 samples have advocated their teachers' kindness. For example, samples (2B, 2D, 3C, 3F, 3H, 6D and 6E) told that,

"My teacher treats every student kindly"

Samples (2P, 7D and 8B) indicated that,

"My teacher is always being kind, even when students commit mistakes"

Samples (2J, 2M, 3B, 6G and 8C) stated that, 
"My teachers' behavior with students is full of love under all situations"

Similar responses like the above were coined under the word "Kindness" by investigators.

\section{Impartial}

Impartial means uniformity in principles for all. Impartial means not prejudiced towards/against any particular side.

Of the 60 samples in this study, 28 have indicated this character. For example, samples (1A, 1E, 6C and 8A) expressed that,

"My teacher treats all students equally without any favoritism"

Samples (1D and 2O) said that,

"My teacher recognizes every student even though they study well or not"

Samples (1B and 6E) indicated that,

"My teacher has an equal view for all students, never lowering them for any reasons". Similar responses like the above were coined under the word "Impartial" by investigators.

\section{Moral Character}

Rules of manners, good characters and general conduct of a person regarding right and wrong are defined as moral character.

Totally 27 samples out of 60 have expressed this character. For example, a sample $6 \mathrm{~F}$ indicated that,

"My teacher maintain professionalism in all areas"

A sample 1A told that,

"My teacher has a work ethics"

A sample $2 \mathrm{~F}$ indicated that,

"My teacher is always sincere in her work"

A sample 2B exclaimed that,

"My teacher is always punctual and treats everyone with disciplined manner"

A sample 2L indicated that,

"My teacher has a moral character and also teaches about it to the students"

A sample 6G stated that,

"Teacher develops moral characters among the students"

Similar responses like the above were coined under the word "Moral Characters" by the investigators.

\section{Humorous}

Funny or amusing quality is known as humorous.

Totally 26 students out of 60 have indicated this character. For example, samples (2G, 3H, 3I, 4B, 4C, 5C, 6A, 6C and 7D) exclaimed that,

"My teacher has a sense of humor"

As ample 8D said that,

"I am always waiting for her class because more fun will be in the class"

Samples (2K, 4D, 4E, 6D and 7C) exclaimed that,

"They taught the lessons with full of fun and joy"

A sample 5D indicated that,

"My teacher, relieves the mental stress of students with their sense of humor"

Similar responses like the above were coined under the word "Humorous" by investigators.

\section{Friendliness}

The quality of being attached to others is known as friendliness.
Totally 25 samples out of 60 expressed this character. For example, samples (1E, 2D, 2F, 3G, 4D, 5A, 6B and 8B) expressed that,

"My teacher always behaves like a friend"

Samples (1A, 1C, 3B and 6E) said that,

"Teachers share everything for their students like a friend"

A sample 3A indicated that,

"Teacher does not maintain distance with students. It is a plus point for my teacher; students can share their problems with him without being afraid"

Samples (2G, 2H, 6D and 7B) told that,

"My teacher treats every student with friendly approach”

Similar responses like the above were coined under the word "Friendliness" by investigators.

\section{Patience}

Patience means capacity to endure trouble.

Totally 25 samples out of 60 have exclaimed about their teacher's patience. For example, a sample $8 \mathrm{E}$ told that,

"How many mistakes the student makes that many times the teacher will explain, my teacher is always patient”

Samples (1C, 3D, 4B, 5H and 8B) said that,

"My teacher taught the lessons with patience and neat"

Samples (2B, 2C, 2D, 2F, 2O, 3C, 3F, 3H, 4D and 6B) indicated that,

"Being patience at any type of situations"

Similar responses like the above were coined under the word "Patience" by investigators.

\section{Subject Knowledge}

Subject knowledge is the knowledge possessed by the teacher's in their respective subject.

Totally 22 samples out of 60 have indicated their teachers' subject knowledge. For example, a sample 8B told that,

"She has good knowledge in the subject and she knows how to apply the subject in day to day life"

Samples (2N, 4A, 4D, 6E, 7D, 7E and 8E) indicated that,

"My teacher is master and expert of his/her subject"

Similar responses like the above were coined under the word "Subject Knowledge" by investigators.

\section{Clarifying Doubts}

To clear the doubts of students is known as clarifying doubts.

Totally 22 samples out of 60 have advocated this character. For example, a sample 8B advocated that,

"My teacher clear student's doubts and she does not bother the number of times to explain"

Samples (1C, 2J, 2K, 3G and 3I) said that,

"To clear their students doubt immediately with a smiling face"

Similar responses like the above were coined under the word "Clarifying Doubts "by investigators.

\section{Common Sense}

Application of general knowledge is called common sense.

Totally 17 samples out of 60 have indicated their teachers' general knowledge. For example, samples (1E, 2J, 2N, 3A, 3D, 3G, 3H and 3I) expressed that,

"My teacher has good general knowledge"

Samples (3C and 6F) said that, 
"My teacher is always rise the general questions in between the class"

Similar responses like the above were coined under the word "Common Sense" by investigators.

\section{Flexibility}

Flexibility means capable of bend or adapting to a situation.

Totally 17 samples out of 60 have expressed their teachers flexibility. For example, a sample 1D advocated that,

"My teacher has a flexible attitude towards students"

A sample 3I told that,

"He is able to see classroom situations from the student's point of view"

Samples (5D, 6E and 2I) said that,

"My teacher adapt to their students need and level"

A sample 2D indicated that,

“They understand to their student's ups and downs and able to work with students with varying levels of maturity and knowledge"

Similar responses like the above were coined under the word "Flexibility" by investigators.

\section{Caring}

Caring means someone to heed other's future and take the part of their successful life.

Totally 16 samples out of 60 have indicated this character. For example, samples (3H, 6F and 6G) exclaimed that,

"My teacher always cares about everything for their students"

A sample 4C said that,

"My teacher does not only care for their students' success; but also for their health, safety and other activities”

Similar responses like the above were coined under the word "Caring” by investigators.

\section{Helping Tendency}

Helping tendency means inclination to assist others.

Totally 14 samples out of 60 have claimed to teachers helping tendency. For example, samples (1A, 2K, 4C and 7B) indicated that,

"To help the students who have problem"

A sample 4A told that,

"To help the poor students in their studying"

Similar responses like the above were coined under the word "Helping Tendency" by investigators.

\section{Guidance}

Guidance means advice or information aimed at resolving a problem or difficulty, especially as given by someone in authority.

Totally 12 samples out of 60 have advocated this character. For example, a sample $6 \mathrm{~F}$ exclaimed that,

"My teacher advice student's, to grow as a human being and to develop academically"

Similar responses like the above were coined under the word "Guidance” by investigators.

\section{TLM}

TLM (Teaching Learning Material) is an aid or thing that is used to assist teaching learning activities.

In the field of Education, TLM is a commonly used acronym that stands for "Teaching Learning Materials." Broadly, the term refers to a spectrum of educational materials that teachers use in the classroom to support specific learning objectives, as set out in lesson plans.
Totally 12 sample out of 60 have claimed this character. For example, a sample $2 \mathrm{~K}$ expressed that,

"My teacher taught the lessons with cardboard, chart and suitable materials"

A sample 4B indicated that,

"My teachers' lessons are always memorable, because he used materials like charts and real life materials"

A sample $2 \mathrm{~F}$ said that,

"She used innovative materials for classroom teaching"

Similar responses like the above were coined under the word “TLM" by investigators.

\section{Motivation}

The act energizing another person is known as motivation.

Totally 10 samples out of 60 have indicated this character. For example, a sample $3 \mathrm{E}$ expressed that,

"My teacher first motivates the students and then teaches the lesson"

A sample 7D told that,

"Prepare the students for the class mentally and physically from their activities"

Similar responses like the above were coined under the word "Motivation" by investigators.

\section{Sports Knowledge}

One's knowledge and their attitude towards sports activity is referred as sports knowledge.

Totally 9 samples out of 60 have expressed this character. For example, a sample 8A exclaimed that,

"Whenever we play the games, my teacher mingles with us"

A sample $3 F$ said that,

"My teacher has a very good knowledge about the sports activities"

Similar responses like the above were coined under the word "Sports Knowledge" by investigators.

\section{Instructional Methodology}

Instructional Methodology is referred as the use of different types of teaching methods by the teacher while teaching.

Totally 9 samples out of 60 have indicated this character. For example, samples (2B, 3E, 5I, 6F and 6G) told that,

"My teacher uses different type of teaching methods while teaching"

Similar responses like the above were coined under the word "Instructional Methodology" by investigators.

\section{Sharing}

Sharing refers to taking part in others feelings and thoughts.

Totally 8 samples out of 60 have advocated this character. For example, a sample 4D expressed that,

"My teacher share everything with us"

A sample 7D indicated that,

"My teacher share our problems with us"

Similar responses like the above were coined under the word "Sharing" by investigators.

\section{Encouragement}

Encouragement is meant by boosting confidence of others.

Totally 8 samples out of 60 have indicated this character. For example, a sample $2 \mathrm{~K}$ told that,

"My teacher always appreciates with claps and rewards upon students answering to her question"

A sample $2 \mathrm{~N}$ expressed that,

"To encourage the students to achieve the goal" 
Similar responses like the above were coined under the word “Encouragement” by investigators.

\section{Language Skill}

Language skill is meant by one's knowledge about the language and fluency of practicing it.

Totally 6 samples out of 60 have expressed this character. For example, a sample $5 \mathrm{H}$ exclaimed that,

"My teacher has good knowledge about the language and has clear speech"

A sample 8C indicated that,

"My teacher has very good voice, reaches everyone and her pronunciations is clear"

Similar responses like the above were coined under the word “Language Skill” by investigators.

\section{Visionary}

One who holds ideals and beliefs for the future is meant by visionary.

Totally 6 samples out of 60 have advocated this character. For example, samples (2B, 2D and 3E) expressed that,

"To give the relevant news about the topic"

A sample 8E said that,

"While teaching lessons my teacher compares with life oriented situations. My teacher teaches how to survive in this society"

Similar responses like the above were coined under the word "Vision" by investigators.

\section{Learning Expert}

Learning expert means one who is eager to learn.

Totally 6 samples out of 60 have indicated this character. For example, samples (1E, 2D and 5F) exclaimed that,

"My teacher is always eager to know the unknown matters"

A sample 6G said that,

"Teacher sometime learns from the students, she is not threatened by a student's thoughtful question"

Similar responses like the above were coined under the word "Learning Expert" by investigators.

\section{Simplicity}

Simplicity means the quality / condition of being easy to understand.

Totally 6 samples out of 60 have advocated this character. For example, a sample 8A said that,

"My teacher is always simple for any matters"

A sample 5D indicated that,

"My teacher tackles any situation with simple manner"

A sample 1A told that,

"My teacher looks like an ordinary human being"

Similar responses like the above were coined under the word "Simplicity" by investigators.

\section{Smiling Face}

Smiling face means an expression of the face indicating pleasure/kindness.

Totally 5 samples out of 60 have indicated this character. For example, a sample 2J claimed that,

"My teacher is always with smiling face"

Similar responses like the above were coined under the word "Smiling Face" by investigators.

\section{Hard Work}

Hard work means doing work with energy and commitment.

Totally 4 samples out of 60 have insisted this character. For example, a sample $3 \mathrm{E}$ expressed that,
"If any work allotted to my teacher, she put the energy to her extreme level"

Similar responses like the above were coined under the word "Hard Work" by investigators.

\section{Self-confident}

Self-confident means high opinion about one's own self. Totally 4 samples out of 60 have indicated this character. For example, a sample $2 \mathrm{O}$ told that,

"My teacher is confident in her abilities and confidently moves into the future"

A sample 2M expressed that,

"My teacher has self-belief about her teaching and other activities"

Similar responses like the above were coined under the word "Self-Confident" by investigators.

\section{Open Mindedness}

The act of seeing truthfulness in statement is referred as open mindedness.

Totally 3 samples out of 60 have indicated this character. For example, a sample 7C exclaimed that,

"She is very frank personality. If any obstacle comes in front of her, she handles that problem with boldness and frank"

Similar responses like the above were coined under the word “Open Mindedness” by investigators.

\section{High Expectation for Students}

Some teacher's expect their students to perform more and beyond the limit. This is referred as high expectations for students.

Totally 3 samples out of 60 have exclaimed this character. For example, a sample 3E said that,

"My teacher believes each and every student can work beyond any imagined limits"

A sample $2 \mathrm{~F}$ indicated that,

"My teacher has high expectations and strives to raise the achievement"

Similar responses like the above were coined under the word "High Expectation for Students" by investigators.

\section{Enjoyability}

Enjoyability is meant as an act of joyful.

Totally 3 samples out of 60 have indicated this character. For example, samples (5D and $8 \mathrm{E}$ ) said that,

"My teacher enjoys her work. He/she seems to have an enormous amount of energy while teaching"

Similar responses like the above were coined under the word "Enjoy ability” by investigators.

\section{Classroom Management}

Classroom management is the management of the students in the classroom.

Totally 3 samples out of 60 have expressed this character. For example, a sample 3A said that,

"Gives enough time to answer the question"

A sample 1D indicated that,

"My teacher gives the time while teaching. It is very useful for us because understanding occur in that time"

A sample 3J told that,

"Maintaining the students attention in the class while teaching"

Similar responses like the above were coined under the word “Classroom Management” by investigators.

\section{Conclusion}


Qualitative analysis of 31 characters has been made from the summary of responses. Thus, successful teacher's profile as perceived by students has been created and is given in the Figure 2. Study [6] predicted professional identity play an important role on teacher's profile. Likewise in this present study, moral character ranks high in the successful teacher's profile. Moral Characters is the base for professional ethics.

Ackermann [9] identified sixteen traits for excellent teachers. They are knowledge of the subject matter, patience, intellectual curiosity, confidence, compassion, achievement, planning, awareness, mentorship, maturity, community involvement, organization, vision, context, mission and enthusiasm. The investigators of this present study also identified 31 characters of a successful teacher. They are teaching, kindness, impartial, moral character, humorous, friendliness, patience, subject knowledge, clarifying doubts, common sense, flexibility, caring, helping tendency, guidance, TLM, motivation, sports knowledge, using instructional technology, sharing, encouragement, language skill, visionary, learning expert, simplicity, smiling face, hard work, self-confident, open mindedness, high expectation for students, enjoyability and classroom management. The traits identified by Eikermann and characters identified by the investigators mostly correlates each other.

Study [5] indicated that new roles are needed for teachers to become carrier for students. In this present investigation also some character which has been relevant to carrier guide has been evolved. They are guidance, sharing, caring, pleasantness, encouragement, high expectation for student and kindness.

The study [8] reveals that the characters of teacher matter more to the student achievement than any other aspect of schooling. By the operational definitions of successful teacher, present study also reveals that the characters of the teacher matter much more to students' success than non-schooling aspects. Further study [8] reports that effective teachers are best identified by the performance. Present study also reports that teaching (which is performance) ranks first among 31 characters.

\section{References}

[1] Teacher Education. (2010). Education. Retrieved on February 11, 2014 from www.teindia.nic.in.

[2] Wikipedia. (2014). Schools and Teacher. Retrieved on February 11, 2014 from http://en.wikipedia.org/wiki/school and teacher.

[3] California state university. (2014). What is the role of a teacher. Retrieved on Februrary 11, 2014 from http://www.csun.edu/ meg75037/paper1.html.

[4] Linda Darling- Hammond. (1999). Teacher quality and student achievement. Centre for the study of teaching and policy, university of Washington.

[5] Mittendorff. (2011, April). Students' perceptions of career conservations with their teachers. Teaching and teacher education: An International Journal of Research and Studies, 27, (3), p 515523.

[6] Canrinus. (2011). Profiling teachers' sense of professional identity. Educational studies, 37, (5), p 593-608.

[7] Tanaka \& Chisato. (2012). Profile and Status of Untrained Teachers: Experiences in Basic Schools in Rural Ghana. A Journal of Comparative and International Education, 42, (3), p 415-438.

[8] Rand education. (2013). Teachers matter: understanding impact on student achievement. Retrieved February 28, 2014 from http://www.rand.Org/education/projects/measuring-teacherseffectiveness-teachers matter.html.

[9] Douglas R. Eikermann. (2014). Sixteen Qualities of A Good Teacher. Retrieved on Februrary 11, 2014 from slingingtheBull.com.

[10] Aggarval, J. E. (2002). Education in emerging India. New Delhi: Doabo house Publishers Ltd.

[11] Henry E. Garrett. (2014). Statistics in Psychology and Education. New Delhi: Surjeet Publications ( $4^{\text {th }}$ Indian Reprint).

[12] John W. Creswell. (2011). Educational Research. (4 ${ }^{\text {th }}$ ed). New Delhi: PHI Learning Private Limited.

[13] Merriam Webster Dictionary. (2014). Mobile version retrieved on July 2014 from http://www.google apps. 